\title{
Isolation and Characterization of B-Sitosterol from Methanol Extracts of the Stem Bark of Large- Leaved Rock Fig (Ficus Abutilifolia Miq)
}

\section{ALIBA, MO;* NDUKWE, IG; IBRAHIM, H}

\author{
Department of Chemistry, Ahmadu Bello University, Zaria, Nigeria \\ *Corresponding Author Email: alibamaryuju@gmail.com
}

\begin{abstract}
This work was aimed at isolating and characterizing some bioactive constituent(s) from the stem bark of Ficus abutilifolia. The phytochemical analysis of the crude methanol extract indicates the presence of flavonoids, alkaloids, cardiac glycosides, saponnins, tannin, steroids and triterpenes. The extract was subjected to column chromatography which resulted in the isolation and purification of a white needle-like crystalline substance with a melting point of $134-136^{0} \mathrm{C}$, the ${ }^{13} \mathrm{CNMR}$ shows recognizable peak at $71.98 \mathrm{ppm}$ assignable to the beta hydroxyl group and the ${ }^{1} \mathrm{HNMR}$ spectrum which shows an olefinic proton at $\delta 5.37$ was identified as $\beta$-sitosterol. Identification of the compound was purely by spectral evidence.
\end{abstract}

\section{DOI: $\underline{\text { https://dx.doi.org/10.4314/jasem.v22i10.19 }}$}

Copyright: Copyright $\left({ }_{0} 2018\right.$ Aliba et al. This is an open access article distributed under the Creative Commons Attribution License (CCL), which permits unrestricted use, distribution, and reproduction in any medium, provided the original work is properly cited.

Dates: Received: 30 September 2018; Revised: 27 October 2018; Accepted: 30 October 2018

Keywords: Ficus abutilifolia, methanol extracts, phytochemical analysis, $\beta$-sitosterol.

Nature in general, has provided mankind with a complete store house of remedies to cure most human ailments Yadav and Singh, (2011). Medicinal plants contain several secondary metabolites such as alkaloids, saponnins, flavonoids, carbohydrates, tannins and anthraquinones which exert biological effects such as antioxidant, anti malaria, antibacterial and anti-inflammatory activities against external agents especially microorganisms Salem et al., (2013). The Ficus species belongs to the family, Moraceae often called the Mulberry family or Fig family is a family of flowering plants comprising about 53 genera and over 1,400 species. Most are widespread in tropical and subtropical regions but a few extend into the temperate regions Singh et al., (2008). F. abutilifolia is a small-medium sized, deciduous-semideciduous tree up to $50 \mathrm{~m}$ high. The bark is whitish yellowish or white and smooth, powdery or somewhat flaking and it is this conspicuous bark that is immediately apparent to the eye. The trunk is usually twisted or contorted, branchless, short and glabrous; lacking hairs and marked with leaf and stipular scars Banso and Adeyemo, (2006). F. abutilifolia miq is known by the common names large leaves rock fig or rock wild fig. The leaves of $F$. abutilifolia are used traditionally to treat various ailments such as typhoid fever, chronic dysentery, sexually transmitted infections, malaria, infertility and the milky latex is used to remove skin warts. The stem bark decoction is taken by men as a strengthening tonic by indigenous communities especially in south eastern and northern parts of Nigeria Ukwulibile, (2014). This research is aimed at the isolation and characterization of the bioactive compound(s) from the stem bark of Ficus abutilifolia.

\section{MATERIALS AND METHOD}

Plant collection and methods: The stem bark of Ficus abutilifolia Miq was collected fresh from Samaru, Zaria in Kaduna State, Nigeria in March, 2017. Taxonomical identification was done at the Herbarium of the Biological Sciences Department, Ahmadu Bello University, Zaria, Nigeria and the voucher number of its deposited specimen in the herbarium is 900742 . The plant bark was air-dried under a shade, segregated and pulverized by manual pounding using wooden mortar and pestle. The pulverized plant material was stored in a cool dry place to avoid moisture from the environment.

Extraction and isolation: Five hundred gram (500 g) of the pulverized stem bark was extracted by cold maceration using 2 liters of methanol at room temperature for 48 hours. The supernatant was filtered through Whatman No.1 filter paper. The extract was dried under reduced pressure using the rotatory evaporator at $40^{\circ} \mathrm{C}$. The quantity extracted was $20 \mathrm{~g}$. The crude extract was subjected to the qualitative phytochemicals analysis using standard methods of Harborne, (1998) (Table 1). Phytochemical screening of the extracts indicated the presence of flavonoids, 
saponins, glycosides, tannins, saponnins, alkaloids, steroids and terpenoids. A small portion of the crude methanol extract was dissolved in $\mathrm{n}$-hexane and the solution was spotted on precoated TLC plates. The TLC plates were developed by specific solvent systems and were viewed individually under UV light at $236 \mathrm{~nm}$ and also sprayed with the Vanillin- $\mathrm{H}_{2} \mathrm{SO}_{4}$ reagent. Through several pilot test experiments it was found out that the compounds of this methanol extract were separated by the solvent system of n-hexane and ethyl acetate in the proportion of 9:1 and the separation was better at 4:1 solvent system. The methanol extract (5 g) was subjected to column chromatography using silica gel (70-230 mesh). The column was packed and eluted with 4:1 n-hexane and ethyl acetate mixture to obtain 32 fractions of $50 \mathrm{mls}$ each. Collected fractions were spotted on a TLC plate and a single spot was observed for A10 and further purification was carried out on it using preparative TLC with a solvent system of 1:4 ethyl acetate and n-hexane to obtain a homogenous A10 compound. This was a white crystalline substance with a melting point of 134 $136^{\circ} \mathrm{C}$. The substance was further subjected to ${ }^{1} \mathrm{H}-$ NMR and ${ }^{13} \mathrm{C}$-NMR spectroscopy.

\section{RESULT AND DISCUSSION}

Phytochemical analysis test: The results of the phytochemical analysis of the crude methanol extracts revealed the presence of alkaloids, flavonoids, steroids/triterpenes, tannins, saponnins and cardiaic glycoside.

Table 1. Phytochemical screenings of the methanol stem bark extract

\begin{tabular}{lllllll}
\hline $\begin{array}{l}\text { Chemical } \\
\text { constituents }\end{array}$ & $\begin{array}{l}\text { Saponnins } \\
\text { Foam test }\end{array}$ & $\begin{array}{l}\text { Tannins } \\
\text { Fecl }_{3} \text { test }\end{array}$ & $\begin{array}{l}\text { Sterols and Triterpenes (Salkowski } \\
\text { and Liebermann-Burchard) }\end{array}$ & $\begin{array}{l}\text { Flavonoid } \\
\text { (Shinoda test) }\end{array}$ & $\begin{array}{l}\text { Glycoside (Keller- } \\
\text { Killian test) }\end{array}$ & $\begin{array}{l}\text { Alkaloids } \\
\text { (Meyers test) }\end{array}$ \\
\hline Stem bark & + & + & + & + & + & + \\
\hline
\end{tabular}

Key: + = present

Table 2. The ${ }^{13} \mathrm{CNMR}$ and ${ }^{1} \mathrm{HNMR}$ spectral values of A10 compared with those obtained from literature Arjun et al., (2010)

\begin{tabular}{|c|c|c|c|c|c|}
\hline Carbon atom & $\begin{array}{l}{ }^{13} \mathrm{CNMR} \\
\text { Experimental }\end{array}$ & $\begin{array}{l}{ }^{1} \mathrm{HNMR} \\
\text { Experimental }\end{array}$ & $\begin{array}{l}{ }^{13} \mathrm{CNMR} \\
\text { Literature }\end{array}$ & $\begin{array}{l}\text { 1HNMR } \\
\text { Literature }\end{array}$ & $\begin{array}{l}\text { Nature of } \\
\text { Carbon atom }\end{array}$ \\
\hline $\mathrm{C}-1$ & 37.39 & & 37.28 & & $\mathrm{CH}_{2}$ \\
\hline $\mathrm{C}-2$ & 31.76 & & 31.69 & & $\mathrm{CH}_{2}$ \\
\hline C-3 & 71.98 & $3.55(\mathrm{~m}, 1 \mathrm{H})$ & 71.82 & $3.53(\mathrm{tdd}, 1 \mathrm{H})$ & $\mathrm{CH}$ \\
\hline C-4 & 42.39 & & 42.33 & & $\mathrm{CH}_{2}$ \\
\hline$C-5$ & 140.88 & $5.37(\mathrm{dd}, 1 \mathrm{H})$ & 140.70 & $5.36(\mathrm{~d}, 1 \mathrm{H})$ & $\mathrm{C}$ \\
\hline C-6 & 121.80 & & 121.72 & & $\mathrm{CH}$ \\
\hline C-7 & 32.06 & & 31.69 & & $\mathrm{CH}_{2}$ \\
\hline C-8 & 29.30 & & 31.93 & & $\mathrm{CH}$ \\
\hline C-9 & 50.28 & & 50.17 & & $\mathrm{CH}$ \\
\hline C-10 & 36.65 & & 36.52 & & $\mathrm{C}$ \\
\hline C-11 & 21.22 & & 21.10 & & $\mathrm{CH}_{2}$ \\
\hline C-12 & 39.92 & & 39.80 & & $\mathrm{CH}_{2}$ \\
\hline C-13 & 42.39 & & 42.33 & & $\mathrm{C}$ \\
\hline C-14 & 56.91 & & 56.79 & & $\mathrm{CH}$ \\
\hline C-15 & 23.21 & & 24.37 & & $\mathrm{CH}_{2}$ \\
\hline C-16 & 28.39 & & 28.25 & & $\mathrm{CH}$ \\
\hline C-17 & 56.21 & & 56.09 & & $\mathrm{CH}$ \\
\hline C-18 & 12.12 & $0.70(\mathrm{~S}, 3 \mathrm{H})$ & 11.86 & $0.63(\mathrm{~S}, 3 \mathrm{H})$ & $\mathrm{CH}_{3}$ \\
\hline C-19 & 19.18 & $1.03(\mathrm{~S}, 3 \mathrm{H})$ & 19.40 & $1.01(\mathrm{~S}, 3 \mathrm{H})$ & $\mathrm{CH}_{3}$ \\
\hline C-20 & 36.29 & & 36.52 & & $\mathrm{CH}$ \\
\hline C-21 & 18.92 & $0.95(\mathrm{~d}, 3 \mathrm{H})$ & 18.79 & $0.93(\mathrm{~d}, 3 \mathrm{H})$ & $\mathrm{CH}_{3}$ \\
\hline C-22 & 34.09 & & 33.98 & & $\mathrm{CH}_{2}$ \\
\hline C-23 & 24.44 & & 26.14 & & $\mathrm{CH}_{2}$ \\
\hline C-24 & 45.98 & & 45.88 & & $\mathrm{CH}$ \\
\hline C-25 & 26.23 & & 28.91 & & $\mathrm{CH}$ \\
\hline C-26 & 19.96 & $0.87(\mathrm{t}, 3 \mathrm{H})$ & 19.80 & $0.84(\mathrm{t}, 3 \mathrm{H})$ & $\mathrm{CH}_{3}$ \\
\hline C-27 & 19.18 & $0.85(\mathrm{~d}, 3 \mathrm{H})$ & 18.79 & $0.83(\mathrm{~d}, 3 \mathrm{H})$ & $\mathrm{CH}_{3}$ \\
\hline C-28 & 22.83 & $0.84(\mathrm{~d}, 3 \mathrm{H})$ & 23.10 & & $\mathrm{CH}_{2}$ \\
\hline C-29 & 9.69 & & 11.99 & $0.81(\mathrm{~d}, 3 \mathrm{H})$ & $\mathrm{CH}_{3}$ \\
\hline
\end{tabular}

Isolation, purification and characterization: the column separation of the methanol extract with a solvent system of 4:1 of n-hexane and ethyl acetate led to the isolation of a compound (A10), which was identified as beta-sitosterol (structure 1) with the following physical properties, chemical and spectral data.

Physical properties: Compound A10 was isolated as a white needle - like crystalline substance with a melting 
point of $134-136^{\circ} \mathrm{C}$ and a molecular formula of $\mathrm{C}_{29} \mathrm{H}_{50} \mathrm{O}$.

Chemical test of the isolated compound: the isolated compound showed positive tests for Salkowski and Liebermann-Burchard test thus confirming the compound as steroid/triterpenoid.

Spectroscopic analysis : ${ }^{1} \mathrm{H}$ NMR (CDCl3, $\left.400 \mathrm{MHz}\right)$; The ${ }^{1} \mathrm{H}$ NMR spectrum of the compound (ppm) showed the presence of six methyl signals that appeared as two methyl sinlgets at $\delta 0.70$, and 1.03 (Fig 1) which corresponds to the angular methyl singlets. Three methyl doublets appeared at $\delta 0.95$, 0.84 , and 0.85 , and a methyl triplet at $\delta$ 0.87 correspounding to the methyl protons. The ${ }^{1} \mathrm{H}$ NMR spectrum of this substance also showed one olefinic proton at $\delta$ 5.37. Its ${ }^{1} \mathrm{H}$ NMR spectrum showed a proton corresponding to the hydroxyl group which appeared as a multiplet at $\delta 3.55 \mathrm{ppm}$.

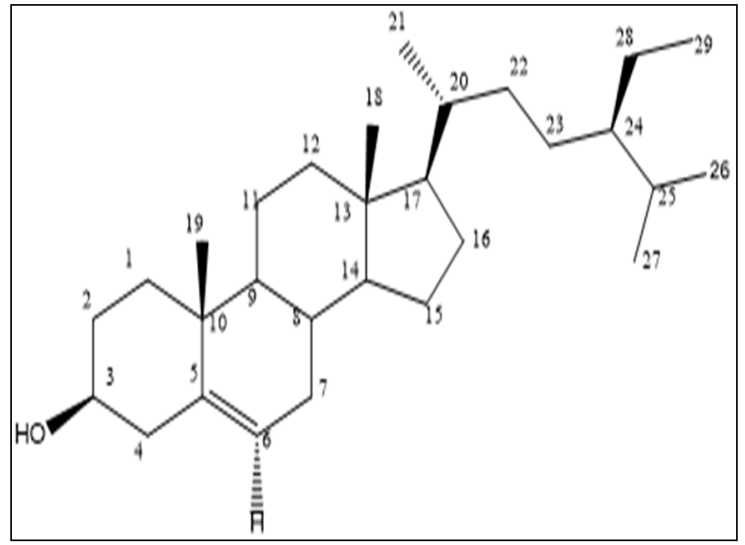

Structure 1. Chemical structure of $\beta$ - sitosterol

Molecular formula: $\mathrm{C}_{29} \mathrm{H}_{50} \mathrm{O}$; Molecular weight: $414 \mathrm{~g} / \mathrm{mol}$; Melting point: $134-136^{\circ} \mathrm{C}$

${ }^{13} \mathrm{C}$ NMR (CDCl3, $\left.100 \mathrm{MHz}\right)$; The ${ }^{13} \mathrm{C}-\mathrm{NMR}$ showed recognizable signals at $140.88 \mathrm{ppm}$ and $121.80 \mathrm{ppm}$ which are typical of alkene double bonds (Fig 2). The values at 19.18 and $12.12 \mathrm{ppm}$ correspond to angular methyl carbon atoms. The signal at $71.98 \mathrm{ppm}$ is assignable to the beta hydroxyl group attached to the carbon at position 3 Structure 1 . The proton and carbon spectral are shown in Figures 1 and 2. The ${ }^{13} \mathrm{C}-\mathrm{NMR}$ spectrum also showed twenty-nine carbon signals made up of six methyl, eleven methylenes, nine methine and three quaternary carbon signals. Based on these results and also by comparism with existing literature the spectral peaks are typical of $\beta$ - sitosterol Arjun et al., (2010). The isolated sitosterol which is a known compound has been reported to possess pharmacological activities such as antifungal and antibacterial, antioxidant and antidiabetic properties, anticancer activities, antihelmitic and antimutagenic activities and anti-inflammatory activity in human systems Soodabeh et al., (2014). The protons and carbons were assigned on the basis of their ${ }^{1} \mathrm{H}$ and ${ }^{13} \mathrm{C}$ NMR shifts given in Table 2.

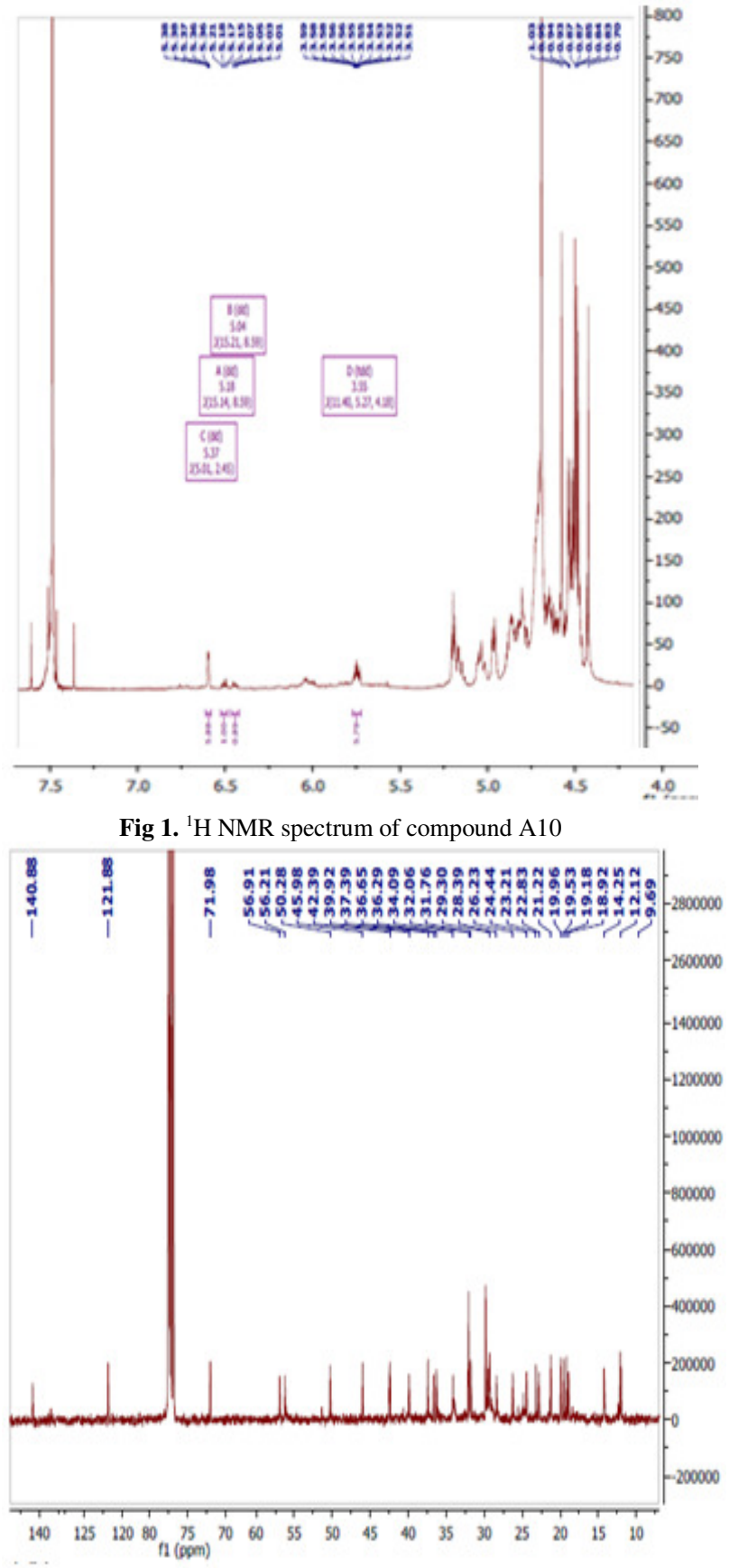

Fig 2. ${ }^{13} \mathrm{C}$ NMR spectrum of compound A10

Conclusion: Compound A10 isolated from the methanol stem bark extracts of Ficus abulitifolia is a phytosterols named $\beta$-sitosterol. The structure of the isolated compound were identified on the basis of spectroscopic methods and by comparing their physical properties reported in the literature. This is 
the first time beta-sitosterol is isolated from the plant of Ficus abutilifolia Miq.

Acknowledgement: The authors wish to thank Aliba family for their support financially and morally. The authors are also grateful to the Department of chemistry Ahmadu Bello University Zaria, for their technical support and contributions toward the success of this research.

\section{REFERENCES}

Arjun, P; Jha, S; Murthy, PN; Manik, AS (2010). Isolation and Characterization of Stigmast-5-en$3 \beta$-ol ( $\beta$ - sitosterol) from the Leaves of Hygrophila spinosa T. Anders. In. J. Pharm. Sci. Res. 1(2): 95-100.

Banso, A; Adeyemo, S (2006). Phytochemical screening and antimicrobial assessment of abutilon mauritianum, Bacopa monnifera and Datura stramonium In. J. Niger. Soc. Expt. boil. 18(1): 39 - 44.

Harborne, JB (1998). Textbook of Phytochemical Methods. 5th Edition, Chapman and Hall Ltd, London. p. 21-72.
Salem, MZM; Salem, AZM; Camacho, LM; Hayssam, MA (2013). Antimicrobial Activities and Phytochemical Composition of Extracts of Ficus Species: An over view. Acad. J. 7(33): 42074219.

Singh, V; Pandey, PC; Jain, DK (2008). Text Book of Botany. Angiosperms. (5th Print - 3rd Edition). Published by Rakesh Kumar Rastogi for Rastogi Publications. New Delhi, India.p. 200-204.

Soodabeh, S; Azadeh, M; Ahmad, RG; Mohammad, A (2014). The Story of Beta-Sitosterol- A Review. European. J. Med. Plants. 4(5): 590-609.

Ukwulibile, CA (2014). Phytochemical Screening and Physical Content Evaluation of Ficus abulitifolia Miq (Moraceae) Leave Stem Barks and Roots for Quantity Control. Scientific J. Crop. Sci. 3(9): 98108.

Yadav, P; Singh, R (2011). A Review on Anthelmintic Drugs and Their Future Scope. In. J. Pharm. 3: 17-21. 